\title{
Sub-micrometer distribution of Fe oxides and organic matter in Podzol horizons
}

\author{
J.-T. Cornelis ${ }^{\mathrm{a}, \mathrm{b}, *}$, B. Delvaux ${ }^{\mathrm{b}}$, E. Van Ranst ${ }^{\mathrm{c}}$, P.G. Rouxhet ${ }^{\mathrm{d}}$ \\ ${ }^{\text {a } U n i v e r s i t y ~ o f ~ L i e g e, ~ G e m b l o u x ~ A g r o-B i o ~ T e c h, ~ W a t e r-S o i l-P l a n t ~ E x c h a n g e s, ~} 5030$ Gembloux, Belgium \\ ${ }^{\mathrm{b}}$ Université catholique de Louvain, Faculté des bioingénieurs, Earth and Life Institute - Soil Science, Croix du Sud L7.05.10, 1348 Louvain-la-Neuve, Belgium \\ ${ }^{c}$ Ghent University, Department of Geology (WE13), Campus Sterre, Krijgslaan 281/S8, 9000 Gent, Belgium \\ d Université catholique de Louvain, Faculté des bioingénieurs, 1348 Louvain-la-Neuve, Belgium
}

\section{A R T I C L E I N F O}

Handling Editor: M. Vepraskas

\section{Keywords:}

Podzol

Spodosol

Organo-mineral associations

Organic matter

Fe oxides

Soil micro-aggregation

SEM

XPS

\begin{abstract}
A B S T R A C T
The spatial distribution of soil constituents at the micrometer scale is of great importance to understand processes controlling the formation of micro-aggregates and the stabilization of organic carbon. Here, the spatial distribution of organic and mineral constituents in Podzol horizons is studied by concerted measurements of (i) the content of various forms of $\mathrm{Fe}, \mathrm{Al}, \mathrm{Si}$ and $\mathrm{C}$ determined by selective extraction in the fine earth fraction of soil (f $<2 \mathrm{~mm}$ ); (ii) the elemental composition of the clay fraction (f $<2 \mu \mathrm{m}$ ) with lateral resolution using scanning electron microscopy with energy-dispersive X-ray spectroscopy (SEM-EDS), and with surface selectivity using X-ray photoelectron spectroscopy (XPS); (iii) the specific surface area (SSA) of fine earth and clay fractions by krypton physisorption.

The SSA of the fine earth in illuvial horizons is predominantly due to finely divided Fe oxides, including goethite, characterized by an equivalent particle size of about $10 \mathrm{~nm}$. Kaolinite platelets of about $2 \mu \mathrm{m}$ size account for a large volume proportion in the clay fraction but have a minor contribution to SSA. Fe oxides and organic matter (OM) are intimately associated. Heterogeneity at the $\mu \mathrm{m}$ scale is created by local variations in the relative amounts of kaolinite and Fe-OM associations. These two kinds of physical entities are in random mixture. Moreover, variation of $\mathrm{C} / \mathrm{Fe}$ atomic ratios reveals sub- $\mu \mathrm{m}$ scale heterogeneity. The latter is due to variation in the relative proportion of organic compounds and Fe oxides, indicating that aggregation of nanoparticles, and not only mere adsorption or pore filling, plays a role in these associations. In this regard, our results highlight that $\mathrm{OM}$ associated with Fe protects Fe oxides against physical displacement and that part of this associated OM is oxidizable by $\mathrm{NaOCl}$ treatment. These findings demonstrate that the concept of OM stabilization through association with Fe must be revisited when considering the sub- $\mu \mathrm{m}$ scale level because fine Fe oxide particles can be easily dispersed during oxidation of associated carbon. Combination of physical fractionation and microanalysis (e.g. SEM-EDS, vibrational spectroscopy) offer promising perspectives to clarify the relationship between chemical composition and sub- $\mu \mathrm{m}$ scale architecture, and to better understand soil processes.
\end{abstract}

\section{Introduction}

The traditional view of soil organic matter (SOM) has long focused on fractions separated after acid and alkaline extractions, and on the formation of large-molecular-sized and persistent "humic" substances. The limitations of this view and of related models on the fate of the organic inputs to soils were assessed by Lehmann and Kleber (2015). The emergent view of a soil continuous model (SCM) focuses on the complexity of soil organic compounds and the dynamics of the interactions between chemical, physical and biological factors. Accordingly "models based on pools should be replaced with models based on organic matter solubility and spatial architecture" (Lehmann and Kleber, 2015).

The co-evolution of soil organic and mineral constituents contributes to the pool of organo-mineral associations (OMA) that partly control the formation of soil aggregates and, in turn, the dynamics of SOM (Six et al., 2002; Schmidt et al., 2011; Kleber et al., 2015). Both the SOM progressive decomposition and reactivity with mineral surfaces in soil aggregates lead to organic molecules with variable stages in the process of mineralization depending on their accessibility to enzymatic activity (Lehmann and Kleber, 2015). SOM is thus partitioned in a continuum, regarding both the nature and lability of its compounds. The more labile organic carbon is readily available for decomposition

\footnotetext{
* Corresponding author at: TERRA Research Centre - Water-Soil-Plant Exchanges Gembloux Agro-Bio Tech, University of Liege (ULiège), 5030 Gembloux, Belgium.

E-mail address: jtcornelis@uliege.be (J.-T. Cornelis).
} 
by microorganisms (Schmidt et al., 2011), while the most stable organic carbon is momentarily preserved from decomposition in a mineralprotected pool, i.e., organic matter associated with mineral constituents (Chenu and Plante, 2006; Mikutta et al., 2009). The progressive decomposition of large biopolymers into smaller molecules through oxidation enhances the reactivity of SOM and its association with metal ions and mineral surfaces. This process can lead to SOM encapsulation in aggregates and protection against the activity of decomposers (Lehmann and Kleber, 2015). The formation of inorganic pedogenic sub-products of mineral weathering together with the progressive decomposition of SOM determine the spatiotemporal evolution of organic carbon and its accessibility to micro-organisms (Oades, 1988; Marschner et al., 2008; von Lutzöw et al., 2008; Schmidt et al., 2011; Dungait et al., 2012; Marín-Spiotta et al., 2014; Basile-Doelsch et al., 2015).

Podzols often exhibit a thick organic mor-moder forest floor revealing a net accumulation of $\mathrm{OM}$ in the topsoil favoured by adverse physico-chemical conditions. Moreover, the quartz-rich nature of their parental material implies a small Acid Neutralizing Capacity (van Breemen et al., 1983). These features promote acidic conditions and poor biological activity. They further enhance the co-transfer of aqueous organic molecules and inorganic ions in the soil profile (Lundström et al., 2000; Sauer et al., 2007), as well as the formation of clay-sized short-range-order ferrihydrite and aluminosilicates (Farmer et al., 1980; Farmer, 1982). The importance of Fe oxide to form OMA is well documented. However, both their evolution during pedogenesis and the relationship between the patchy distribution of $\mathrm{C}$ at particle surfaces and $\mathrm{Fe}$ oxides have yet not been elucidated.

Since organic and inorganic constituents accumulate in illuvial podzolic subsoil horizons (De Coninck, 1980; Farmer et al., 1980; Farmer, 1982; Van Ranst et al., 1997; Buurman and Jongmans, 2005), podzolization is a model soil-forming process to study the sub- $\mu \mathrm{m}$ spatial distribution of $\mathrm{OM}$ and Fe oxides, and the influence of pedogenesis on the stability of OMA. Here we assess the spatial distribution of elements ( $\mathrm{Si}, \mathrm{Al}, \mathrm{Fe}, \mathrm{C}$ ) and relevant phases oxide to clarify how the spatial heterogeneity of the interactions between constituents affects the stability of OMA. The amounts of inorganic and organic constituents are determined by chemical analyses, following selective chemical extractions. The identification of the clay-sized mineral phases of key samples by X-ray diffraction (XRD) and infrared spectroscopy (FTIR) was complemented by other advanced analytical techniques: (i) scanning electron microscopy with energy-dispersive X-ray spectroscopy (SEM-EDS) to focus on the spatial distribution of chemical elements; (ii) X-ray photoelectron spectroscopy (XPS) which provides a chemical analysis of the first nm below the surface exposed by the sample, and (iii) specific surface area determination using krypton physisorption which provides information in terms of equivalent particle size.

\section{Materials and methods}

\subsection{Study site}

The selected Podzol pedon belongs to a weathering soil sequence (Herbauts, 1982), located on the Lower Lias outcrop in Southeast Belgium (Belgian Lorraine). The altitude ranges between 300 and $350 \mathrm{~m}$, the annual rainfall amounts to $1100 \mathrm{~mm}$ and the mean annual temperature is $7.7^{\circ} \mathrm{C}$ (Herbauts, 1982). The bedrock is a calcareous sandstone (Lower Lias age). The parent material consists of an autochthonous sandy layer, formed by the dissolution of the calcareous bedrock, overlaid by a mixture of this sandy material with fine quartzrich loessic silt-sized particles (Herbauts, 1982). The sequence shows an increased Podzol development from Dystric Cambisol to Carbic Podzol (IUSS Working Group WRB, 2015). According to Herbauts (1982), podzolization is a current active process driven by the quartz-rich nature of parent material, acidic moder-mor litter under dominant beech, and humid climate. One of the traits is the fate of Al which is involved in the chloritization of 2:1 phyllosilicates in OM-poor horizons, but in complexation with OM in OM-rich horizons (Herbauts, 1982). Palynological studies (Munaut, 1967) and ${ }^{14} \mathrm{C}$ datation (Herbauts, 1982) further show that the podzolization process started around 4500-5000 years ago (formation rate of E horizon $\sim 0.08 \mathrm{~mm}$ / yr), and that the mean residence time (years) of OC ranges between $95 \pm 75$ and $85 \pm 75$.

The Carbic Podzol represents the most advanced weathering stage in the sequence, and was selected for this study. The soil samples were collected in each horizon: AE-E (eluvial) - Bhs (enriched in humic acids and Fe oxides) - Bs (enriched in Fe oxides) - Bw (weakly colored; separated into Bw1 and Bw2) - BC (slightly weathered parent material). The samples were air-dried, then sieved ( $<2 \mathrm{~mm}$ ) and homogenized.

\subsection{Physico-chemical characterization of the fine earth fraction $(f<2 \mathrm{~mm})$}

The particle size analysis was carried out by collecting quantitatively the clay, silt and sand fractions. Sand fractions (f $>50 \mu \mathrm{m}$ ) were collected by wet sieving after ultrasonication ( $w / v$ ratio $1: 3$, applied energy of $300 \mathrm{~J} \cdot \mathrm{min}^{-1}$; Balesdent et al., 1991) and OM oxidation in $6 \%$ $\mathrm{H}_{2} \mathrm{O}_{2}$. Silt and clay fractions were then separated through sedimentation after dispersion with $\mathrm{Na}$ hexametaphosphate. The $\mathrm{pH}$ was measured in $\mathrm{H}_{2} \mathrm{O}$ (10 g:25 ml). Exchangeable cations were extracted by $1 \mathrm{M}$ $\mathrm{CH}_{3} \mathrm{COONH}_{4}$ at $\mathrm{pH} 7$ for $\mathrm{Ca}^{2+}, \mathrm{Mg}^{2+}, \mathrm{K}^{+}, \mathrm{Na}^{+}$and by $1 \mathrm{M} \mathrm{KCl}$ for $\mathrm{H}^{+}$ and $\mathrm{Al}^{3+}$. The sum of these cations is the effective cation exchange capacity (ECEC). The specific surface area (SSA) was determined by krypton physisorption at liquid $\mathrm{N}_{2}$ temperature $(77 \mathrm{~K})$ using a Micromeritics ASPA 2000 instrument (UCL-IMCN/MOST). Before the measurements, $100 \mathrm{mg}$ of sample were outgassed at $120^{\circ} \mathrm{C}$ overnight under vacuum (0.67 Pa). The Brunauer, Emmett and Teller (BET) equation (Brunauer et al., 1938) was used to determine the SSA from adsorption data in the range of 0.05 to 0.30 relative pressures.

The organic debris from the fine earth samples were removed by water flotation at density of $1.0 \mathrm{~g} \cdot \mathrm{cm}^{-3}$. Soil samples $(\sim 4 \mathrm{~g})$ were slurried in $40 \mathrm{ml}$ of deionized water, shaken for $4 \mathrm{~h}$, and centrifuged at $314 \mathrm{~g}$ for $15 \mathrm{~min}$. The supernatant was removed and the pellet was dried at $105^{\circ} \mathrm{C}$. The total carbon content (TOC) was measured on ground samples through dry combustion with a CNS analyzer (Flash EA 1112 Series). A subsample was treated with $\mathrm{NaOCl}$ as detailed by Mikutta et al. (2006): $3 \mathrm{~g}$ of soil was reacted with $30 \mathrm{ml}$ of $6 \mathrm{wt} \% \mathrm{NaOCl}$ at $\mathrm{pH} 8$ adjusted by adding $32 \% \mathrm{HCl}$; after $6 \mathrm{~h}$ of slow mixing at $21 \pm 1{ }^{\circ} \mathrm{C}$, the suspension was centrifuged $(314 g ; 15 \mathrm{~min})$ and the supernatant was removed; the extraction with $\mathrm{NaOCl}$ was repeated twice more. The $\mathrm{NaOCl}$-treated samples were washed five times with $20 \mathrm{ml}$ deionized water, dried at $40{ }^{\circ} \mathrm{C}$, weighted and submitted to carbon analysis. A portion was then extracted further with hydrofluoric acid (HF) in order to ensure dissolution of all the mineral constituents: $2 \mathrm{~g}$ of the dried $\mathrm{NaOCl}$-treated sample was transferred into a pre-weighed centrifugal bottle and reacted with $20 \mathrm{ml} 10 \% \mathrm{HF}$; after shaking for $2 \mathrm{~h}$ at $21 \pm 1{ }^{\circ} \mathrm{C}$, the suspension was centrifuged $(314 g ; 15 \mathrm{~min})$ and the supernatant was discarded; the extraction with HF was repeated three times more. The pellets were washed five times with $20 \mathrm{ml}$ deionized water, dried at $105^{\circ} \mathrm{C}$, weighted and submitted to carbon analysis. The carbon concentrations measured in the $\mathrm{NaOCl}$ and $\mathrm{HF}$ treated samples were converted into concentrations in the initial sample. This provides the contents of two categories of carbon: ROC, i.e. the content left in the residue after treatment with $\mathrm{NaOCl}$ and $\mathrm{HF}$ (tentatively considered as "recalcitrant carbon"), and MPOC, i.e. the result of subtracting ROC from the content measured after $\mathrm{NaOCl}$ treatment (tentatively attributable to "mineral-protected carbon"; Kleber et al., 2005; Mikutta et al., 2006). The distinction of these categories in TOC is motivated by the assumption that $\mathrm{NaOCl}$ treatment which mimics natural oxidative processes, does not dissolve pedogenic oxides and only slightly dissolves $\mathrm{Al}$ from the short-range-order minerals (Lavkulich and Wiens, 1970; Siregar et al., 2005). 
$\mathrm{Fe}, \mathrm{Al}$ and $\mathrm{Si}$ were extracted from the soil samples using dark acid ammonium oxalate $0.2 \mathrm{M}$ (o) and dithionite-citrate-bicarbonate (DCB) (d) (Dahlgren, 1994). Their concentrations in the extracts were measured by inductively coupled plasma atomic emission spectrometry (ICP-AES; Thermo Jarrell Ash, IRIS Advantage). DCB-extracted $\mathrm{Fe}\left(\mathrm{Fe}_{\mathrm{d}}\right)$ is considered to include crystalline and short-range-order Fe oxides (Mehra and Jackson, 1960), and organo-Fe complexes (Wada, 1989). Dark oxalate dissolves short-range-order minerals such as allophanic substances (Wada, 1989), ferrihydrite (Cornell and Schwertmann, 1996), and organo-metallic compounds (Dahlgren, 1994).

\subsection{Physico-chemical characterization of the clay fraction $(f<2 \mu \mathrm{m})$}

\subsubsection{Separation and treatment}

The clay fraction $(<2 \mu \mathrm{m}$ on the basis of a particle density of $2.65 \mathrm{~g} \cdot \mathrm{cm}^{-3}$ ) from E, Bhs, Bs, Bw1 and BC horizons was separated after dispersion with $\mathrm{Na}^{+}$-resin, without any chemical pretreatment (Rouiller et al., 1972) in order to avoid surface contamination (Gerin et al., 2003). This method is very efficient to disperse micro-aggregated soils such as Ferralsols (Bartoli et al., 1991) and Andosols (Ndayiragije and Delvaux, 2003). Besides, in the absence of $\mathrm{H}_{2} \mathrm{O}_{2}$ removal of OM, it preserves organic compounds in their respective particle size fractions. $4 \mathrm{~g}$ of fine earth was sonicated in $100 \mathrm{ml}$ of deionized water during $3 \times 1 \mathrm{~min}$ (90 J per min; Balesdent et al., 1991). The suspension was then sieved at 50 mesh. The fraction retained on the sieve was re-suspended in deionized water and sonicated; then the process of sieving and re-suspension was performed three times more, which left a clear supernatant. The liquids collected by sieving were pooled, sonicated (w/v ratio 1:3, applied energy of $300 \mathrm{~J} \cdot \mathrm{min}^{-1}$; Balesdent et al., 1991), dispersed with $\mathrm{Na}^{+}$resin through $\mathrm{Na}^{+}$saturation (Rouiller et al., 1972), and centrifuged at $11 \mathrm{~g}$ for $3.5 \mathrm{~min}$. The pellet was re-suspended in deionized water, sonicated and centrifuged. This operation was repeated three or four times until the supernatant was clear. A mild sonication was used to limit disturbance in the clay fraction; however the latter may originate from coatings of sand and silt fractions (Balesdent et al., 1991). The supernatants were pooled, centrifuged at $1968 \mathrm{~g}$ for $10 \mathrm{~min}$, and finally re-suspended in methanol and incubated overnight in an oven at $105^{\circ} \mathrm{C}$, providing the clay fraction $(<2 \mu \mathrm{m})$.

A subsample of the clay fraction of Bhs was treated with DCB (DCBBhs) to dissolve Fe oxides. Furthermore, a subsample of the clay fraction of Bhs and Bw1 horizons was oxidized using a treatment with $\mathrm{NaOCl}(6 \%$ at $\mathrm{pH} 8)$ as described above, with the aim to remove easilyoxidizable organic compounds.

\subsubsection{Analytical methods}

The bulk concentration of inorganic elements in the clay fractions was determined after calcination at $950^{\circ} \mathrm{C}$ followed by borate fusion (Chao and Sanzolone, 1992). Briefly, a crushed sample of $150 \mathrm{mg}$ of the ignition residue was melted at $1000{ }^{\circ} \mathrm{C}$ in a graphite crucible in the presence of $0.4 \mathrm{~g}$ Li-tetraborate and $1.6 \mathrm{~g}$ Li-metaborate. After the dissolution of fusion beads in $10 \% \mathrm{HNO}_{3}$ under magnetic agitation at $100{ }^{\circ} \mathrm{C}$, elemental contents were determined by ICP-AES. The bulk concentration of each element is expressed as mole per $\mathrm{kg}$ of clay-sized material (dry weight at $105{ }^{\circ} \mathrm{C}$ ), accounting for the weight loss due to calcination.

The surface analysis of the clay fractions was performed by X-ray photoelectron spectroscopy (XPS), using a SSX 100/206 photoelectron spectrometer from Surface Science Instruments (USA) equipped with a monochromatized micro-focused Al X-ray source (powered at $20 \mathrm{~mA}$ and $10 \mathrm{kV}$ ). The samples were pressed in a small stainless steel cylinder of $4 \mathrm{~mm}$ diameter and $0.5 \mathrm{~mm}$ depth and placed on an aluminium carousel. The pressure in the analysis chamber was about $10^{-6} \mathrm{~Pa}$. The angle between the perpendicular to the sample surface and the axis of the analyzer lens was $55^{\circ}$. The analyzed area was approximately $1.4 \mathrm{~mm}^{2}$ and the pass energy was set at $150 \mathrm{eV}$ for the survey scan and $50 \mathrm{eV}$ for narrow scans. Under these conditions, the full width at half maximum (FWHM) of the Au $4 \mathrm{f}_{7 / 2}$ peak of a clean gold standard sample was about $1.1 \mathrm{eV}$. A flood gun set at $6 \mathrm{eV}$ and a Ni grid placed $3 \mathrm{~mm}$ above the sample surface were used for charge stabilization. The following sequence of spectra was recorded: survey spectrum, C $1 \mathrm{~s}$, O $1 \mathrm{~s}$, $\mathrm{N} 1$ s, $\mathrm{Al} 2 \mathrm{p}, \mathrm{Si} 2 \mathrm{p}$ Fe 2p, Ca 2 s, $\mathrm{Mg} \mathrm{KL}_{23} \mathrm{~L}_{23}$ and $\mathrm{C} 1 \mathrm{~s}$ again to check the stability of sample charging with time. Data treatment was performed with the CasaXPS program (Casa Software Ltd., UK). The C 1s peak component due to carbon only bound to carbon and hydrogen was fixed to $284.8 \mathrm{eV}$ in order to set the binding energy scale. Molar fractions (percentage over all elements except hydrogen) were calculated using peak areas determined with a Shirley baseline and a normalization based on acquisition parameters and sensitivity factors provided by the manufacturer (mean free path varying according to the 0.7 th power of the photoelectron kinetic energy; Scofield cross sections; transmission function assumed to be constant). The Fe concentration was determined from the Fe $2 \mathrm{p}_{3 / 2}$ peak.

The SSA of the clay fractions was determined as described for fine earth samples. XRD analysis was performed on the clay fraction from Bhs and Bw1 horizons after removal of OM using $\mathrm{H}_{2} \mathrm{O}_{2}$. XRD patterns were collected with a Bruker Advance diffractometer using CuKa radiation. FTIR spectra of the clay fraction from the E, Bh and Bs horizons were recorded with a IFS55 Equinox Fourier Transform infrared spectrometer (Brücker) equipped with a DTGS detector, using 200 scans and a resolution of $1 \mathrm{~cm}^{-1}$. Disks of $13 \mathrm{~mm}$ diameter were pressed after mixing $5 \mathrm{mg}$ sample with $200 \mathrm{mg} \mathrm{KBr}$ (Janssens Chimica, 99\%), and drying at $150{ }^{\circ} \mathrm{C}$ to remove moisture. Spectra were also recorded on sample $-\mathrm{KBr}$ mixtures heated at $350^{\circ} \mathrm{C}$ in order to check the evolution of the $\mathrm{OH}$-stretching bands attributed to kaolinite.

Clay fractions from Bhs and Bw1 horizons were examined by scanning electron microscopy, combined with SEM-EDS to assess the micro-scale distribution of elements ( $\mathrm{Fe}, \mathrm{Al}, \mathrm{Si}$ and $\mathrm{C}$ ). This examination was also performed on the Bhs and Bw1 subsamples treated with $\mathrm{NaOCl}$. Droplets of suspensions were dried on a Si wafer piece used as a support. The images were obtained on a FEG-SEM Zeiss Ultra55, with a beam energy of $5 \mathrm{keV}$, using the signal of secondary electrons. EDS analysis was performed with the same instrument equipped with a Bruker Quantax system (XFlash Silicon Drift Detector; the diameter of the volume analyzed is $0.5 \mu \mathrm{m}$ ). For each sample of interest, the EDS analysis was performed on at least 3 different images with 3 spots per image.

\section{Results}

\subsection{Properties of the fine earth fraction $(f<2 \mathrm{~mm})$}

Table 1 presents the particle size distribution, $\mathrm{pH}_{\mathrm{H} 2 \mathrm{O}}$, contents of oxalate (o) and DCB (d) extractable Si, Al and Fe, ECEC, and SSA. This table also gives the contents of TOC and of the categories MPOC (referring tentatively to "mineral-protected carbon") and ROC (referring tentatively to "recalcitrant carbon"), keeping in mind that the physical meaning of such partitioning is quite relative (Lehmann and Kleber, 2015).

As expected, the evolution of $\mathrm{Fe}_{\mathrm{o}}, \mathrm{Fe}_{\mathrm{d}}$ and organic carbon concentrations with depth shows a large accumulation in Bhs and Bs.

\subsection{Properties of the clay fraction $(f<2 \mu \mathrm{m})$}

XRD diagrams of non-oriented powders are presented in Fig. 1. Clay-sized kaolinite $(0.712 \mathrm{~nm})$, quartz $(0.334 \mathrm{~nm})$ and goethite $(0.417 \mathrm{~nm})$ occur in Bhs and Bw. The FTIR spectra (data not presented) show $\mathrm{OH}-$ stretching bands typical of kaolinite (two sharp peaks at 3620 and $3700 \mathrm{~cm}^{-1}$ separated by a peak of about half their height; Rouxhet et al., 1977) with about the same intensity for the clay fractions of $\mathrm{E}, \mathrm{Bhs}$ and Bs horizons.

The values of elemental contents ( $\mathrm{Si}, \mathrm{Al}, \mathrm{Fe}$ ) and SSA are given in Table 2. The Fe concentration is the largest in $\mathrm{Bs}$ whereas the $\mathrm{Al}$ 
Table 1

Major physico-chemical characteristics of the Podzol horizons. Concentrations of elements are given in mmol $\mathrm{kg}^{-1}$ of soil dried at $105^{\circ} \mathrm{C}$.

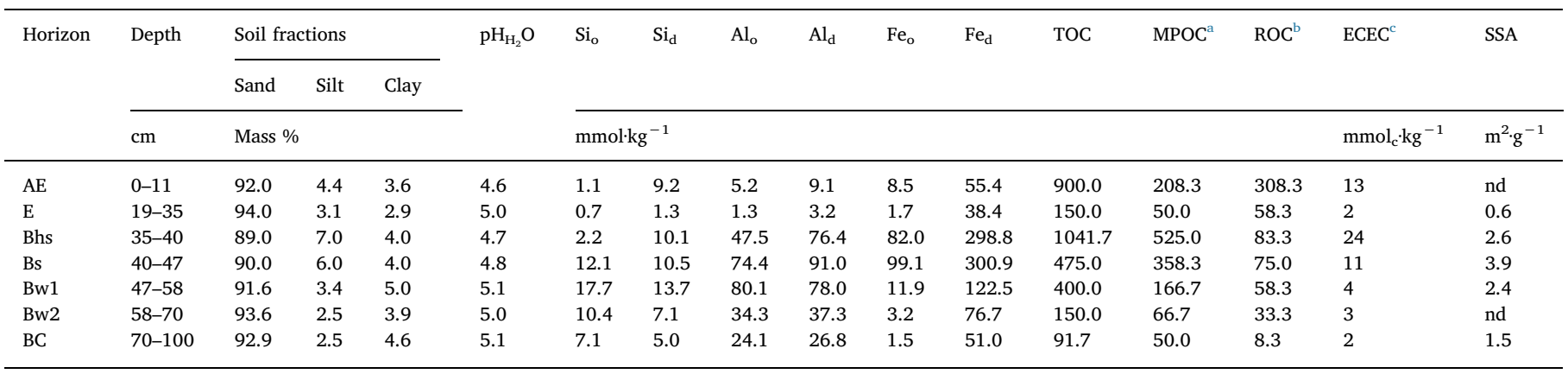

$\mathrm{o}=$ oxalate-extractable $\mathrm{Si}, \mathrm{Fe}$ and $\mathrm{Al} ; \mathrm{d}=\mathrm{DCB}$-extractable $\mathrm{Si}, \mathrm{Fe}$ and $\mathrm{Al} ; \mathrm{nd}=$ not determined.

a MPOC: resistant to $\mathrm{NaOCl}$ and extracted by $\mathrm{HF}$ treatment.

b ROC: resistant to HF treatment.

${ }^{\mathrm{c}} \mathrm{mmol}_{\mathrm{c}} \mathrm{kg}^{-1}=$ millimoles of charge per $\mathrm{kg}$ soil.

concentration increases with depth. The DCB-Bhs clay sample exhibits a very small Fe content, thereby confirming the efficiency of the DCB extraction. The SSA follows the same trend as the Fe concentration. Indeed, the largest SSA value occurs in $\mathrm{Bs}\left(80 \mathrm{~m}^{2} \cdot \mathrm{g}^{-1}\right)$, while the lowest one is measured in DCB-Bhs $\left(9 \mathrm{~m}^{2} \cdot \mathrm{g}^{-1}\right)$.

Surface analysis by XPS provides carbon concentrations ranging from 29 to $41 \%$. The C 1 s peak shape does not differ markedly from that of adventitious organic contaminants always detected in XPS analysis of oxides (Landoulsi et al., 2016); consequently it did not provide significant information on the relative abundance of different functional groups in SOM. The oxygen concentration varies from 45 to $53 \%$. The shape of the C 1s peak allows quantifying oxygen from organic compounds (Landoulsi et al., 2016). The concentration of oxygen from inorganic compounds deduced by difference accords with combinations of stoichiometries of $\mathrm{SiO}_{2}, \mathrm{Al}(\mathrm{OH})_{3}$, kaolinite $\left[\mathrm{Al}_{2} \mathrm{Si}_{2} \mathrm{O}_{5}(\mathrm{OH})_{4}\right]$, and $\mathrm{FeOOH}, \mathrm{Fe}(\mathrm{OH})_{3}$ or organic complex of $\mathrm{Fe}(\mathrm{OH})_{2}{ }^{+}$, but does not provide a significant information on their relative importance. The mole fractions of $\mathrm{Si}, \mathrm{Al}$ and $\mathrm{Fe}$ with respect to the sum $(\mathrm{Si}+\mathrm{Al}+\mathrm{Fe})$, as measured by XPS, are given in Table 2 . Their evolution through the pedon is presented in Fig. 2 and compared with the respective mole fractions computed from the bulk composition.

Fig. 3 illustrates the SEM micrographs as well as the peak intensities of $\mathrm{C}, \mathrm{Fe}, \mathrm{Al}$ and $\mathrm{Si}$ as measured by EDS in Bhs clay. The intensity of each of the $\mathrm{C}, \mathrm{Al}, \mathrm{Si}$ and Fe peaks recorded by EDS was measured in absolute values. Their conversion into molar ratios may not be performed owing to the multiphasic nature of the samples and the lack of adequate standards. Therefore, the absolute intensities are compared with each other, without any normalization, as presented in Fig. 4. It is important to check that the apparent relationships illustrated in this figure do not result from anomalies generated by the influence of $\mathrm{Fe}$ on $\mathrm{C}, \mathrm{Al}$ and $\mathrm{Si}$
Table 2

Bulk composition (mole $\mathrm{kg}^{-1}$ dried at $105^{\circ} \mathrm{C}$ ), specific surface area, and surface composition (mole fraction in $\%$ with respect to the sum of the $\mathrm{Si}, \mathrm{Al}$ and Fe concentrations) of the clay fractions.

\begin{tabular}{|c|c|c|c|c|c|c|c|c|}
\hline \multirow[b]{3}{*}{ Horizon } & \multirow[b]{3}{*}{ Depth } & \multicolumn{7}{|c|}{ Clay fraction } \\
\hline & & \multicolumn{4}{|c|}{ Bulk composition } & \multicolumn{3}{|c|}{ Surface composition } \\
\hline & & $\mathrm{Si}$ & $\mathrm{Al}$ & $\mathrm{Fe}$ & SSA & $\mathrm{Si}$ & $\mathrm{Al}$ & $\mathrm{Fe}$ \\
\hline & $\mathrm{cm}$ & \multicolumn{3}{|c|}{ mole $\cdot \mathrm{kg}^{-1}$} & $\mathrm{~m}^{2} \cdot \mathrm{g}^{-1}$ & \multicolumn{3}{|l|}{$\% \mathrm{~mol}$} \\
\hline E & 19-35 & 6.59 & 2.81 & 1.95 & 19 & 0.61 & 0.31 & 0.08 \\
\hline Bhs & $35-40$ & 3.52 & 2.88 & 2.60 & 30 & 0.43 & 0.39 & 0.17 \\
\hline Bs & $40-47$ & 3.18 & 3.57 & 3.52 & 80 & 0.33 & 0.42 & 0.25 \\
\hline Bw1 & $47-58$ & 3.61 & 4.72 & 2.32 & 43 & 0.33 & 0.59 & 0.07 \\
\hline $\mathrm{BC}$ & $70-100$ & 5.06 & 5.17 & 2.48 & 39 & 0.39 & 0.52 & 0.09 \\
\hline DCB-Bhs* & $35-40$ & 5.90 & 3.61 & 0.18 & 9 & 0.56 & 0.44 & 0.00 \\
\hline
\end{tabular}

DCB-Bhs: Dithionite-Citrate-Bicarbonate treated clay fraction of Bhs.

intensities. The possible influence of the presence of Fe on the intensity ratios $\mathrm{C} / \mathrm{Al}$ and $\mathrm{Si} / \mathrm{Al}$ is evaluated using data for spots characterized by large Fe peak intensity. The apparent molar ratios are computed using the computer software Esprit v1.9, considering the effective Fe intensity of 6700 , on the one hand, and assuming it is zero, on the other hand. The deduced C/Al molar ratios are 0.48 and 0.53 , respectively, while the $\mathrm{Si} / \mathrm{Al}$ ratios are 0.93 and 0.97 , respectively. The same calculation performed on another spot, considering the effective Fe intensity of 7532 and assuming it is zero, provides $\mathrm{C} / \mathrm{Al}$ molar ratios of 0.83 and 1.02 , respectively, and $\mathrm{Si} / \mathrm{Al}$ ratios of 1.35 and 1.28 , respectively. This demonstrates that the relationships between the intensity ratios and the

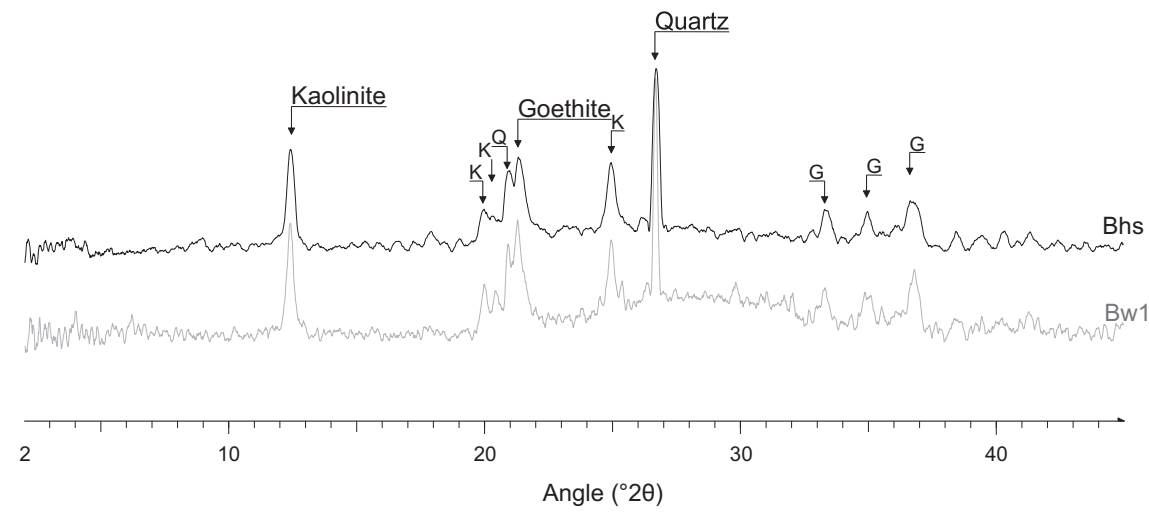

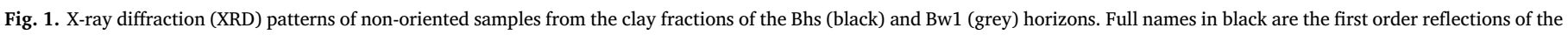
main minerals. Letters are assignments of other peaks ( $\mathrm{G}=$ goethite, $\mathrm{K}=$ kaolinite and $\mathrm{Q}=$ quartz). 

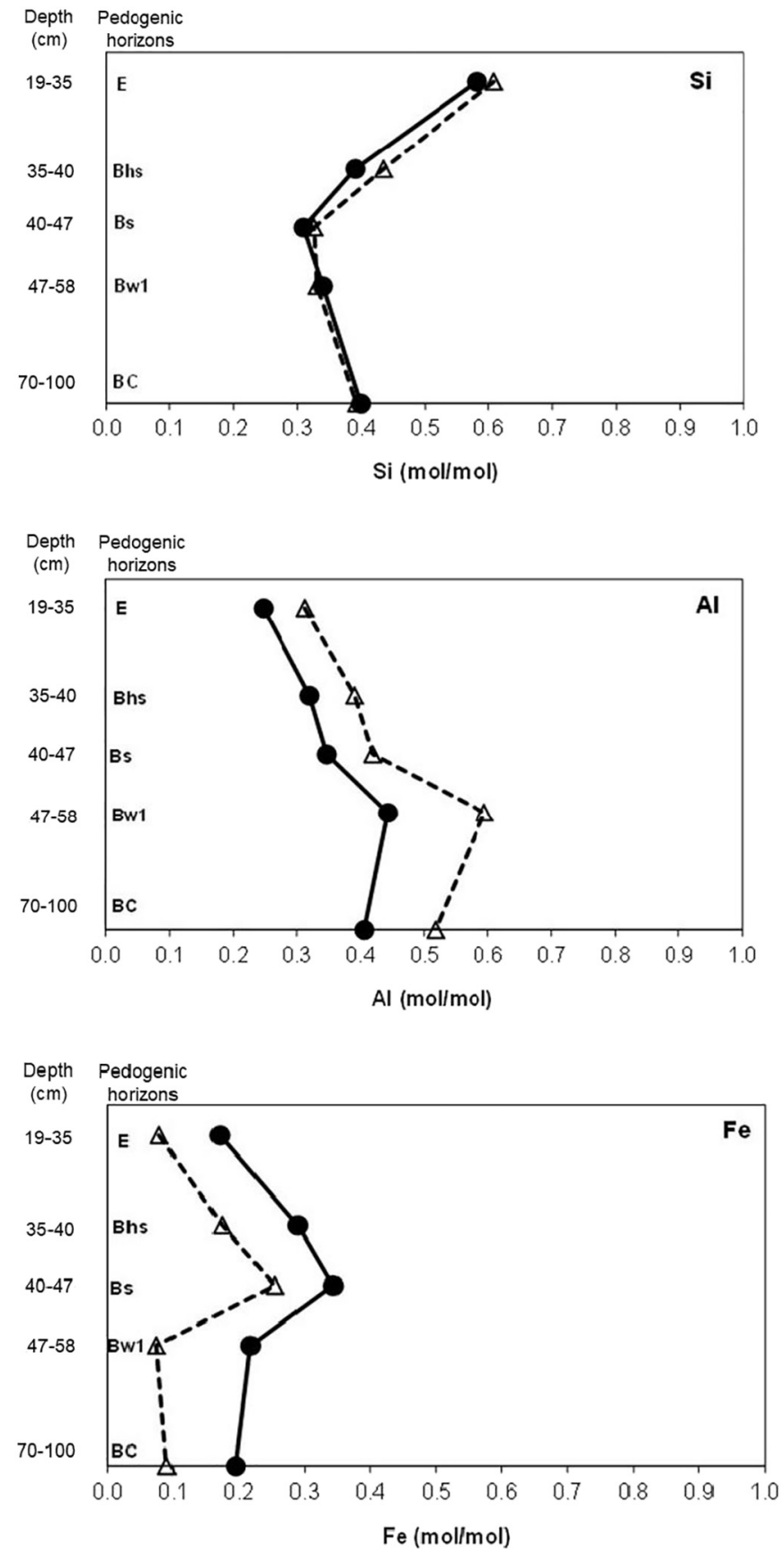

Fig. 2. Evolution of $\mathrm{Si}, \mathrm{Al}$ and $\mathrm{Fe}$ contents (mole fraction with respect to $\mathrm{Si}+\mathrm{Al}+\mathrm{Fe}$ ) of clay fractions (solid line, $\bullet$ : bulk analysis; dashed line, $\triangle$ : X-ray photoelectron spectroscopy analysis) in the Podzol profile.

concentration ratios for $\mathrm{C}, \mathrm{Si}$ and $\mathrm{Al}$ are not influenced by a variation of the Fe concentration. It is also important to check that the apparent relationships expressed in Fig. 4 do not result from any unwanted effect of the silicon wafer used as sample holder. The EDS analysis of three spots of a $\mathrm{Si}$ wafer used as sample substrate provides Si peak intensities of $152 \times 10^{3} \pm 30 \times 10^{3}$, with peak intensities of C (1,274 \pm 263$)$, $\mathrm{Fe}(533 \pm 230)$ and $\mathrm{Al}(836 \pm 138)$ which are much smaller than the ones measured for the samples of interest as shown in Fig. $4 \mathrm{~b}$ and $\mathrm{c}$. This indicates that the sample holder does not interfere appreciably with the samples.

SEM-EDS data reveal the presence of numerous plate-like particles (spot 2 in Fig. 3a and spot 1 in Fig. 3b), of about $2 \mu \mathrm{m}$ size, which are characterized by large and similar $\mathrm{Si}$ and $\mathrm{Al}$ peak intensities, as illustrated in Fig. 3. These particles exhibit the typical morphology of kaolinite, as evidenced by XRD and FTIR. Round shape particles (spot 1 in Fig.3a) showing a large Si peak intensity and very small $\mathrm{Fe}$ and $\mathrm{Al}$ peak intensities are probably micro-grains of quartz. Sub-micrometer sized aggregates are observed with various concentrations of $\mathrm{C}, \mathrm{Fe}, \mathrm{Al}$ and $\mathrm{Si}$.

Fig. 4 plots the EDS Si, Fe, $\mathrm{Al}$ and $\mathrm{C}$ peak intensities against each other for the Bhs and Bw1 clay fractions both treated and not treated with $\mathrm{NaOCl}$. For the sake of clarity, 8 spots out of 37 are excluded from all plots: (i) 6 spots are merely silica with intensity ratios Si/Al $>50$ and Si peak intensities above 23,000 ( 2 spots for Bhs, 3 spots for NaOCltreated Bhs, 1 spot for NaOCl-treated Bw1); and (ii) 2 spots are merely $\mathrm{Fe}$ oxide, with intensity ratios $\mathrm{Fe} / \mathrm{C}>10, \mathrm{Fe} / \mathrm{Al}>4$ and $\mathrm{Fe}$ intensities above 19,000 (1 spot for Bhs and 1 spot for Bw1). The correlations are positive between $\mathrm{Si}$ and $\mathrm{Al}$ signals ( $r=0.87$; Fig. 4a), negative between Fe and $\mathrm{Al}$ signals $(r=-0.86$; Fig. 4c). The correlation between $\mathrm{C}$ and Fe signals is positive, but scattered ( $r=0.73$; Fig. 4b). Noteworthy is the fact that the Bhs clay fraction is characterized by more dispersed $\mathrm{C} / \mathrm{Fe}$ intensity ratios and a wider range of $\mathrm{C}$ peak intensities (500 to 7000) than those observed in the Bw1 clay fraction (500 to 2000). The NaOCl treatment of Bw1 left a material showing negligible $C$ intensities with some spots (not presented in Fig. 4) constituted merely of either pure silica or pure $\mathrm{Fe}$ oxide. The $\mathrm{NaOCl}$ treatment of Bhs also reduced the range of $\mathrm{C}$ and Fe intensities but left spots with a significant value of these intensities.

\section{Discussion}

\subsection{Correlations between data in the fine earth fraction ( $f<2 \mathrm{~mm}$ )}

Correlation coefficients between the different variables collected for fine earth samples, except AE horizon (Table 1) were computed. The correlation coefficient between $\mathrm{Fe}_{\mathrm{o}}$ and $\mathrm{Fe}_{\mathrm{d}}$ is very large $(r=0.98)$. Yet the proportion of $\mathrm{Fe}_{\mathrm{o}}$ with respect to $\mathrm{Fe}_{\mathrm{d}}$ content ranges between 2 and $15 \%$ in $\mathrm{AE}, \mathrm{E}, \mathrm{Bw}$ and $\mathrm{BC}$ horizons, but amounts to $27-33 \%$ in Bhs and Bs horizons. This means that the proportion of short-range-order Fe oxide is largest in the illuvial B horizons. The correlations between $\mathrm{Fe}_{\mathrm{d}}$ and, respectively, MPOC $(r=+0.96)$ and TOC $(r=+0.85)$ further illustrate the expected relationships between the accumulations of $\mathrm{OM}$ and Fe oxides (Fig. 5). The plot of MPOC against TOC $(r=+0.96$; not shown) shows evenly distributed data points and a linear regression equation $\mathrm{MPOC}=0.53 * \mathrm{TOC}-1.5$. Moreover the variation of the MPOC/TOC ratio is small: standard deviation of 0.13 for an average value of 0.50 . This indicates a lack of significant variation, throughout the profile, of the proportion of OM which would be protected from degradation through association with inorganic phases.

SSA is positively correlated with both oxalate- and DCB-extractable $\mathrm{Al}$ and $\mathrm{Fe}(0.85 \leq r \leq 0.97)$. The relationship between SSA and $\mathrm{Fe}_{\mathrm{d}}$ is shown in Fig. 6a and will be discussed in the next section. These correlation coefficients are not significantly modified if Bhs fine earth is excluded from the set of samples. In contrast, correlations of SSA with TOC and MPOC $(r=+0.53$ and +0.72 , respectively, for the whole set of samples) become much stronger $(r=+0.88$ and +0.96 , respectively) if Bhs sample is excluded. This reveals that the association of OM with $\mathrm{Fe}$ oxides can impede the increase of the SSA controlled by $\mathrm{Fe}$ oxides. Such an observation would have been missed if concentrations had been expressed as mass fractions.

ECEC is correlated with $\mathrm{Fe}_{\mathrm{o}}$ and $\mathrm{Fe}_{\mathrm{d}}(r=0.82$ and 0.87 , respectively), and TOC and MPOC $(r=0.97)$. However the relationship between ECEC and SSA deserves more attention. The mean value of the ECEC/SSA ratio amounts to $2.29 \mu \mathrm{mol}_{\mathrm{c}} \cdot \mathrm{m}^{-2}$ in E, Bs, Bw1and BC, but to $9.23 \mu \mathrm{mol}_{\mathrm{c}} \cdot \mathrm{m}^{-2}$ in Bhs. The latter value is much larger than the surface charge density which is physically possible on a solid surface. For comparison, the surface charge density of smectite ranges between 1.1 and $2.2 \mu$ mole $_{\mathrm{c}} \cdot \mathrm{m}^{-2}$ (Shainberg et al., 1987) whereas the amount of water in an adsorbed monolayer is $15.4 \mu \mathrm{mole} \cdot \mathrm{m}^{-2}$ (Rouxhet and Brindley, 1966). Accordingly, a large proportion of OM accumulated in 



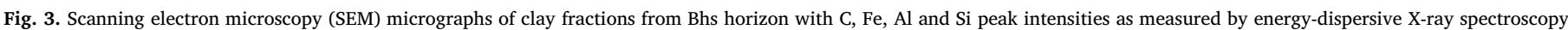
(EDS) on spots 1, 2 and 3 in 2 images (a and b).

Bhs may be viewed as a sponge, collapsed when dry but able to swell in water and to show a high cation-exchange capacity. This behaviour is typical of ion exchange resins and observed for oxidized carbon fibers (Pamula and Rouxhet, 2003).

These observations corroborate that the accumulation of Fe and OM are related with each other; the SSA is due to Fe oxides (Eusterhues et al., 2005a). The Bhs sample significantly differs from other samples regarding the relationship between $\mathrm{OM}, \mathrm{Fe}$ oxides and interfacial properties. This must be considered with caution owing to the limited set of samples; however, this assessment will be further supported by SEM-EDS and XPS data.

\subsection{Colloidal constituents: nature and distribution}

The clay fractions contain goethite, kaolinite and quartz (Fig. 1), the latter two occurring as micrometric particles (Fig. 3). Plate-like particles of about $2 \mu \mathrm{m}$ in size are kaolinite, which is responsible for the large $\mathrm{Si} / \mathrm{Fe}$ and $\mathrm{Al} / \mathrm{Fe}$ atomic ratios. The average $\mathrm{Al} / \mathrm{Si}$ intensity ratio of about 1 (Fig. 4a) indicates that the intensity ratio, as measured by SEM$\mathrm{EDS}$, is close to the $\mathrm{Al} / \mathrm{Si}$ atomic ratio attributed to kaolinite.

The soil depth variation of the relative concentrations of $\mathrm{Si}, \mathrm{Al}$ and Fe in clay fractions follows the same trend for both the surface and bulk measurements, with a marked accumulation of $\mathrm{Fe}$ in Bhs and Bs horizons (Fig. 2), analogous to the soil fine earth (Table 1). The similarity of surface and bulk concentrations for $\mathrm{Si}$ and $\mathrm{Al}$ is consistent with a mere mixture of quartz and kaolinite particles. The systematically lower value of the surface relative $\mathrm{Fe}$ concentration $[\mathrm{Fe} /(\mathrm{Si}+\mathrm{Al}+\mathrm{Fe})]$ compared to the bulk concentration (Fig. 2) is attributed to the privileged association of $\mathrm{OM}$ with $\mathrm{Fe}$-containing phases, in contrast with $\mathrm{Si}$ and $\mathrm{Al}$-containing phases.

While the results indicate a mere mixture of quartz, kaolinite and Fe-rich particles, one may not infer the absence of coating of the former ones by the latter as a disturbance may have been provoked by dispersion and drying involved in the clay fraction separation.
The SEM-EDS results show that the clay fraction separation provides distinct particles of aluminosilicates and entities in which iron and organic compounds are preferentially located. The latter are described as organans (Van Ranst et al., 1980). The removal of SOM by wet oxidation ( $\mathrm{NaOCl}$ treatment) leads to a removal of $\mathrm{Fe}$ (Fig.4b) presumably in the form of suspended oxide nanoparticles. Yet the remaining material contains $\mu \mathrm{m}$-sized aggregates which are merely pure Fe oxides, presumably goethite. This observation is in contradiction with the idea that $\mathrm{OM}$ associated with $\mathrm{Fe}$ oxides is resistant against oxidation (Kleber et al., 2015) and with the assumption that MPOC represents that part of carbon which is protected through associations with minerals. While Fe-bearing phases protect OM from microorganisms (Eusterhues et al., 2005b; Kögel-Knabner et al., 2008; Eusterhues et al., 2014), our data further shows that OM protects Fe-bearing phases from dispersion and other forms of physical displacement.

Fig. 7 plots SSA of the fine earth samples against SSA of the corresponding clay fractions. The regression equation gives a small intercept $\left(0.29 \mathrm{~m}^{2} \cdot \mathrm{g}^{-1}\right)$, and a slope of 0.045 which is in the range of the soil clay content ( 3 to $5 \%$; Table 1 ). This is consistent with the fact that soil SSA is essentially due to clay-sized particles. Fig. 6a plots SSA against total Fe concentration of the clay fractions, including DCB-Bhs. Fe oxides thus play a major role in the development of SSA, as compared to aluminosilicates. According to Fig. $6 \mathrm{a}, 1 \mathrm{~mol}$ of Fe accounts for a SSA in the range of 10,000 to $20,000 \mathrm{~m}^{2}$. The value of $10,000 \mathrm{~m}^{2}$ is perfectly consistent with the relationship between SSA and $\mathrm{Fe}_{\mathrm{d}}$ content in the fine earth (Fig.6b). A surface area of $10,000 \mathrm{~m}^{2} / \mathrm{mol} \mathrm{Fe}$ corresponds to $112 \mathrm{~m}^{2} \cdot \mathrm{g}^{-1}$ if $\mathrm{Fe}$ is in the form of FeOOH. Assuming that SSA is due to spherical particles of diameter $\mathrm{d}$, relevant for amorphous particles, or needles with a square section of width $\mathrm{w}$, relevant for goethite, the sizes are related to SSA as follows:

$d=6 *(\rho * S S A)^{-1}$ or $\mathrm{w}=4 *(\rho * S S A)^{-1}$

where $\rho$ is the particle density, assumed to be that of goethite $4.28 \mathrm{~g} \cdot \mathrm{cm}^{-3}$ Accordingly, the equivalent particle diameter or needle 

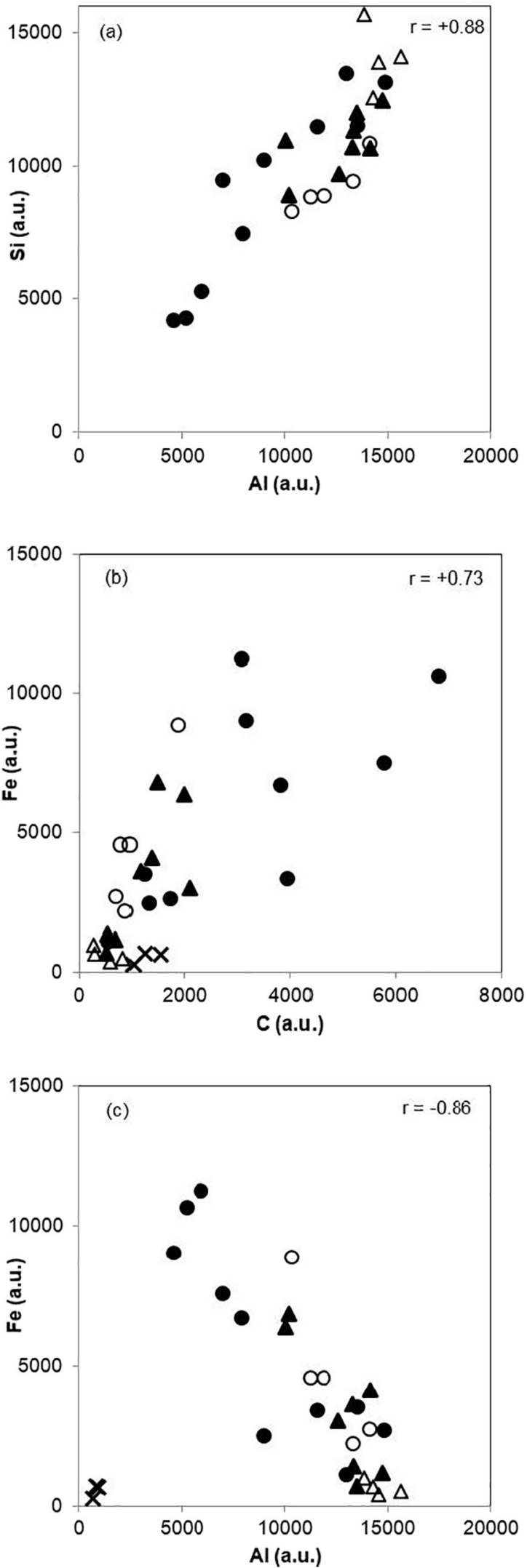

Fig. 4. Plots of peak intensities (arbitrary units) of $\mathrm{Fe}, \mathrm{Al}, \mathrm{C}$ and $\mathrm{Si}$ as measured by Scanning electron microscopy and Energy-dispersive X-ray spectroscopy (SEM-EDS) on the clay fractions of Bhs $(\bullet)$ and $\operatorname{Bw} 1(\boldsymbol{\Lambda})$ horizons, and on the respective NaOCl-treated clay fractions $(\mathrm{Bhs}=\mathrm{O}$; Bw1 $=\triangle$ ). Measurements performed on the Si wafer are represented by a cross in (b) and (c).

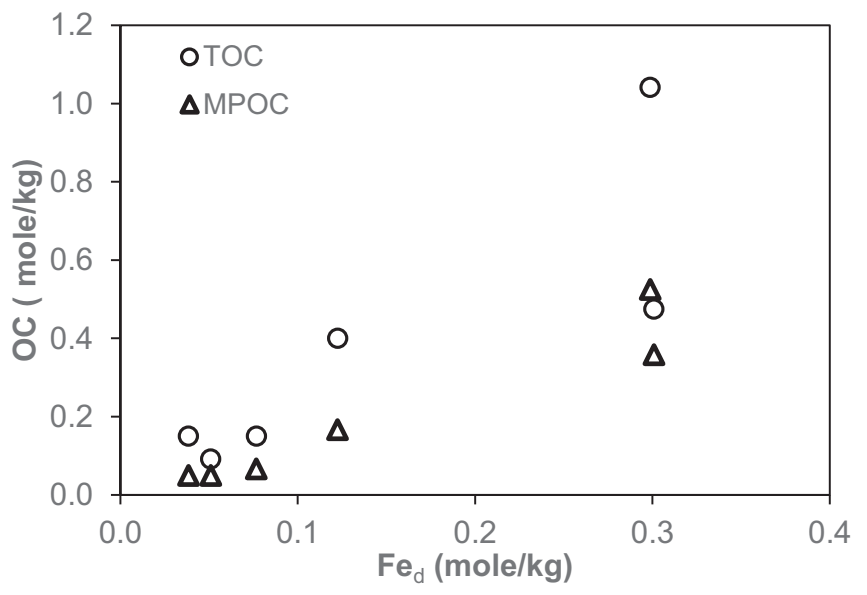

Fig. 5. Plot of the organic carbon concentrations (O: TOC; $\triangle$ : MPOC) of the fine earth fraction against DCB-extractable $\mathrm{Fe}$ content $\left(\mathrm{Fe}_{\mathrm{d}}\right)$.

width would be 12 or $8 \mathrm{~nm}$, respectively. Considering furthermore the possibility of $20,000 \mathrm{~m}^{2}$ per mole $\mathrm{Fe}$, the equivalent sizes of $\mathrm{Fe}$ oxide particles range between 4 and $12 \mathrm{~nm}$. This order of magnitude is not biased by assumptions regarding particle shape and stoichiometry, or by possible particle aggregation with pore formation.

The data concerning DCB-Bhs (Table 2) indicates that $1 \mathrm{~mol}$ of $\mathrm{Al}$ present in the clay fraction may account for a SSA of about $2500 \mathrm{~m}^{2}$, which is much smaller compared to that associated with Fe. If this SSA is considered to be developed by the faces of platelets, the platelet thickness $(t)$ is related to SSA by:

$t=2 *(\rho * \mathrm{SSA})^{-1}$.

Considering the stoichiometry and density of kaolinite $\left[\mathrm{Si}_{2} \mathrm{Al}_{2} \mathrm{O}_{5}(\mathrm{OH})_{4} ; 2.65 \mathrm{~g} \cdot \mathrm{cm}^{-3}\right]$ provides a platelet thickness of $40 \mathrm{~nm}$. These calculations demonstrate that the main aluminosilicate particles are appreciably coarser than the Fe oxides, which is in agreement with SEM-EDS observations.

The incidence of OM on SSA requires attention, because of the cross correlations occurring between SSA, $\mathrm{Fe}_{\mathrm{d}}$ and MPOC in the fine earth samples. The interaction between $\mathrm{OM}$ and $\mathrm{Fe}$ oxides has stimulated much interest in relation to the accessibility of OM to microbial and enzymatic activities (Schmidt et al., 2011; Lehmann and Kleber, 2015). It has been reported that adsorption of natural OM by synthetic goethite $\left(73 \mathrm{~m}^{2} \cdot \mathrm{g}^{-1}\right)$ decreases the specific surface area by pore filling (Kaiser and Guggenberger, 2007). In that study, the adsorption plateau was about $1.9 \mathrm{mg}$ carbon $/ \mathrm{m}^{2}$ initial goethite, corresponding to a volume of $0.95 \mathrm{~cm}^{3} \mathrm{OM} / \mathrm{cm}^{3}$ goethite, considering OM density of $1.4 \mathrm{~g} / \mathrm{cm}^{3}$ (Mayer et al., 2004) and an carbon concentration of $441 \mathrm{mg} \cdot \mathrm{g}^{-1}$ (Kaiser and Guggenberger, 2007). Under these conditions, the specific surface area was reduced to $32 \mathrm{~m}^{2} \cdot \mathrm{g}^{-1}$ goethite. The ratio of micropore $(<2 \mathrm{~nm})$ volume to goethite volume, equal to 0.189 , accounted for a large proportion of the specific surface area and was reduced to 0.025 after adsorption; the ratio of mesopore $(2-50 \mathrm{~nm})$ volume to goethite volume was reduced from 0.071 to 0.008 as a result of adsorption. Note that the volume of adsorbed OM was much larger than the pore volume; as a matter of fact, SEM-EDS observations revealed the presence of voluminous aggregates of goethite and organic compounds.

Fig. 5 shows the MPOC/Fe $/ e_{\mathrm{d}}$ molar ratio of fine earth samples is about 1.3; the molar ratio $\mathrm{TOC} / \mathrm{Fe}_{\mathrm{d}}$ is about twice more. Considering the density and carbon concentration of OM reported by Kaiser and Guggenberger (2007), a MPOC/ $\mathrm{Fe}_{\mathrm{d}}$ molar ratio of 1.3 corresponds to an $\mathrm{OM} / \mathrm{FeOOH}$ volume ratio of 1.2 . This is amazingly close to the volume ratio obtained by Kaiser and Guggenberger (2007) from laboratory experiments. However, the variation of the $\mathrm{C} / \mathrm{Fe}$ ratio at the micrometer scale, revealed by SEM-EDS for Bhs shows that OM/Fe oxide ratio has no straightforward physical meaning owing to the complex material 


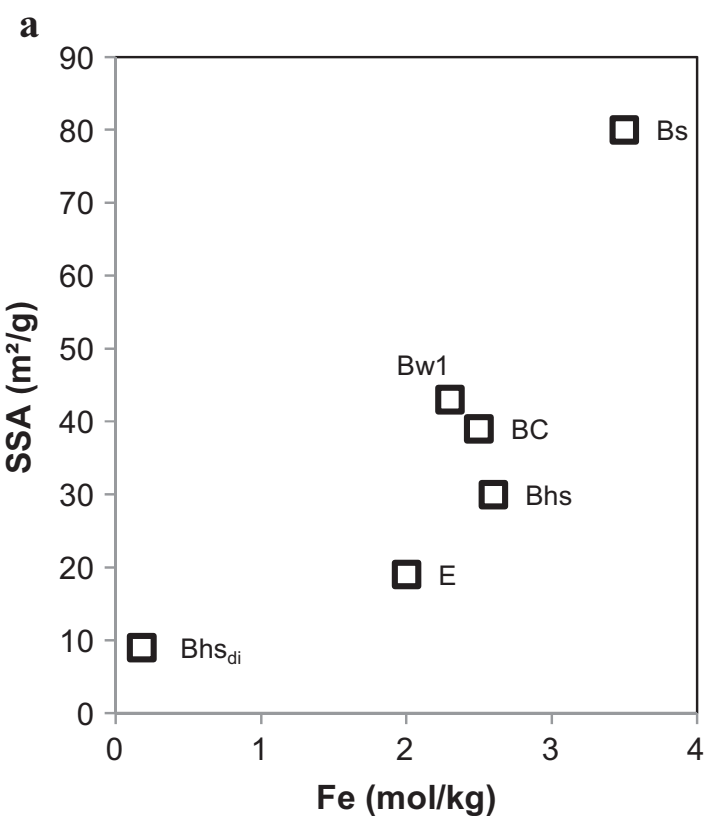

b

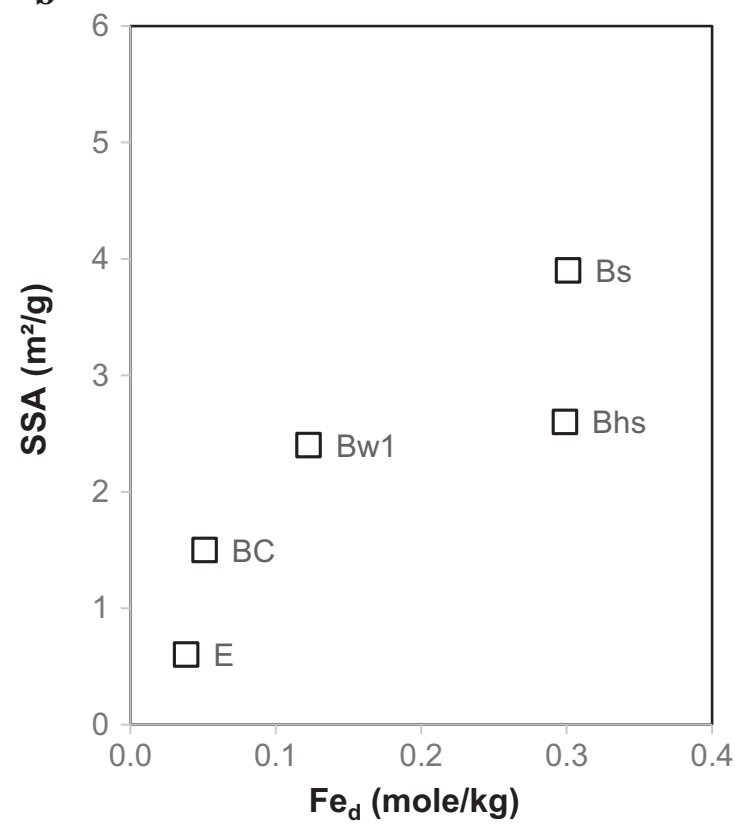

Fig. 6. (a) Plot of specific surface area (SSA) against the bulk Fe concentration, both in the clay fractions; (b) Plot of SSA against DCB-extractable $\mathrm{Fe}\left(\mathrm{Fe}_{\mathrm{d}}\right)$, both in the fine earth.

architecture. Our observations, combined with laboratory experiments (Kaiser and Guggenberger, 2007) show that the formation of aggregates of $\mathrm{Fe}$ oxides with organic macromolecules or nanoparticles must be considered in addition to (i) the formation of a defined adsorbed organic layer on an inorganic surface and/or (ii) the filling of the pores of an inorganic adsorbent.

Table 1 and Figs. $6 \mathrm{~b}$ and 5 indicate that the Bhs fine earth sample is characterized by a large $\mathrm{TOC} / \mathrm{Fe}_{\mathrm{d}}$ ratio and a small $\mathrm{SSA} / \mathrm{Fe}_{\mathrm{d}}$ ratio. This explains that the correlation coefficients between SSA and TOC or MPOC increase if this sample is excluded, as mentioned above. The SEM-EDS examination of the clay fraction of Bhs (Figs. 3 and 4) reveals spots which are characterized not only by a low concentration of $\mathrm{Al}$ and $\mathrm{Si}$ but also by a large $\mathrm{C} / \mathrm{Fe}$ ratio. The heterogeneity of the $\mathrm{C} / \mathrm{Fe}$ concentration ratio of Bhs clay fraction, and its relatively small SSA, may possibly be related to differences in the relative importance of different

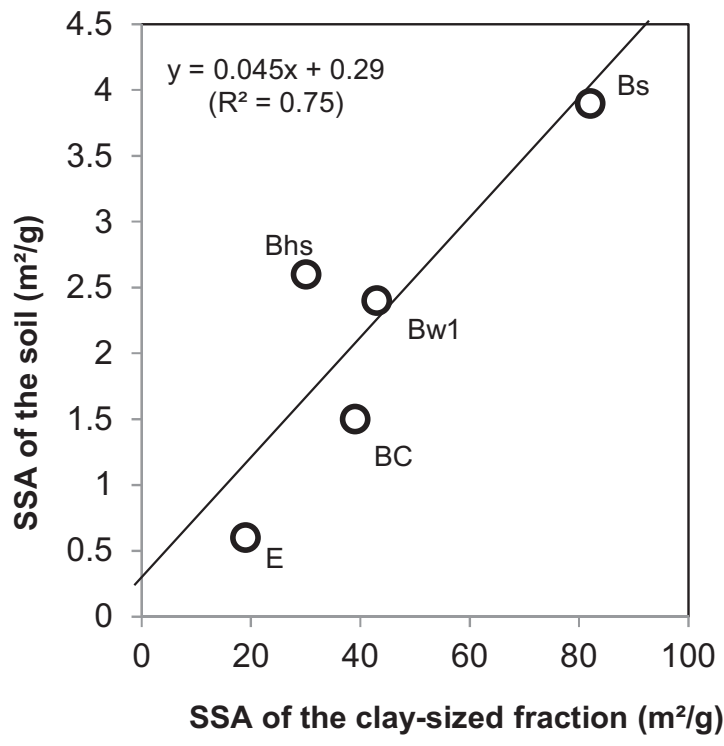

Fig. 7. Relationship between the specific surface area (SSA) of the fine earth samples and their respective values in corresponding clay fractions.

forms of OM (molecules adsorbed on, molecules blocking pores of, nanoparticles aggregated with Fe oxide), confirming the interest of the unified model of OM-mineral interactions suggested by Basile-Doelsch et al. (2015).

Furthermore, the question may be raised whether the spatial distribution of $\mathrm{OM}$ at the sub-micrometer scale, i.e. the material architecture, is linked to a variation of OM chemical nature (Lehmann and Kleber, 2015). This question is important regarding the mechanisms of accumulation, the stability of OM, and even the color specificity of Bhs with respect to other horizons. It could be answered by extending this study to a larger set of samples, and other types of soils substantially affected by Fe chemistry, such as in Andosols, Gleysols, Ferralsols. Nitisols, Umbrisols and Cambisols, and in soils with one of the following qualifiers: spodic, andic, ferralic, nitic. Application of technical advances in soil science can be very promising by focusing on spatial resolution, combining microscopic techniques and methods of physical fractionation according to both particle size and density. In this respect, vibrational spectroscopy (IR, Raman) applied to controlled fractions or in the microscope mode are most promising. Of particular interest is the evaluation of the relative concentrations of chemical functions, of the relative importance of $\mathrm{sp}^{2}$ and $\mathrm{sp}^{3}$ carbon hybridization, and of the size of aromatic sheets (Rouxhet et al., 1980; Abdallah and Yang, 2012; Parikh et al., 2014). Atomic force microscopy makes it possible to image physico-chemical properties, such as electrical properties and hydrophobicity, with nanoscale resolution (Alsteens et al., 2007). Nano secondary ion mass spectrometry (NanoSIMS) seems to be a powerful technique for studying the distribution of elements and chemical functions at nanoscale, with C and $\mathrm{N}$ isotope selectivity (Mueller et al., 2012). NanoSIMS analyses of soil incubated with litter have shown that the newly-incorporated $\mathrm{OM}$ is heterogeneously distributed, with preferential retention by organo-mineral clusters with rough surfaces containing pre-existing OM (Vogel et al., 2014).

\section{Conclusion}

The SSA developed by the soil material of the illuvial horizons of the studied profile is mainly due to finely divided Fe oxides, predominantly goethite. The equivalent particle size of these Fe oxides is of the order of $10 \mathrm{~nm}$. Kaolinite platelets of the order of $2 \mu \mathrm{m}$ account for a large volume proportion in the clay fraction but have a minor contribution to the SSA.

The soil material can be visualized as quartz-rich sand grains coated 
by, or mixed with colloidal sub- $\mu \mathrm{m}$ particles. The latter are aluminosilicate minerals, mainly kaolinite, and entities in which Fe oxides and $\mathrm{OM}$ are intimately associated. A heterogeneity at the $\mu \mathrm{m}$ scale is created by the varying local proportion of kaolinite and "Fe-OM associations", both making a random mixture after separation of the clay fraction. Moreover, the variation of the $\mathrm{C} / \mathrm{Fe}$ concentration ratio reveals a sub$\mu \mathrm{m}$ scale heterogeneity due to a variation of the proportion of organic compounds with respect to Fe oxides, indicating that the aggregation of nanoparticles plays a role in these organans.

This representation supports the picture of soil reactive micro-spots, or rather nanoscale sites, which result from and control further the fate of the soluble organo-mineral complexes according to physico-chemical conditions (Masiello et al., 2004; Schmidt et al., 2011; Torn et al., 2013; Basile-Doelsch et al., 2015). It highlights the importance of the architecture of the associations between Fe oxides and OM, which involves aggregate formation and not only mere adsorption of organic compounds by inorganic phases or pore filling.

The SEM-EDS observations showed that particles below the $\mu \mathrm{m}$ range are differentiated according to a combination of size and specific gravity. Accordingly, refined physical fractionation and the use of appropriate micro- or nano-analytical techniques offer promising perspectives to clarify the relationship between chemical composition (inorganic and organic compounds, organic chemical functions) and sub- $\mu \mathrm{m}$ scale architecture, which is a key to better understand the dynamic processes occurring through the soil profile. (Lehmann and Kleber, 2015). Soil and environmental science may benefit from latest progresses headed by material science and biophysics, particularly from the characterization of chemical composition and physico-chemical properties with nanoscale resolution.

\section{Acknowledgements}

The authors acknowledge A. Iserentant, C. Givron, A. Lannoye, H. Titeux, I. Caignet, M. Genet, L. Ryelandts, M. Jacquemin and E. Gaigneaux (UCL) for field and laboratory assistance, and Prof. Em. J. Herbauts for his assistance and clever advices. J-T.Cornelis. was supported by "Fonds National de la Recherche Scientifique" of Belgium (FNRS; Postdoctoral Researcher Grant).

\section{References}

Abdallah, W.A., Yang, Y., 2012. Raman spectrum of asphaltene. Energy Fuel 26, 6888-6896.

Alsteens, D., Dague, E., Rouxhet, P.G., Baulard, A.R., Dufrêne, Y.F., 2007. Direct measurement of hydrophobic forces on cell surfaces using AFM. Langmuir 23, 11977-11979.

Balesdent, J., Pétraud, J.-P., Feller, C., 1991. Effets des ultrasons sur la distribution granulométrique des matières organiques des sols. Science du Sol 29, 95-106.

Bartoli, F., Burtin, G., Herbillon, A.J., 1991. Disaggregation and clay dispersion of oxisols: Na resin, a recommended methodology. Geoderma 49, 301-317.

Basile-Doelsch, I., Balesdent, J., Rose, J., 2015. Are interactions between organic compounds and nanoscale weathering minerals the key drivers of carbon storage in soils? Environ. Sci. Technol. 49, 3997-3998.

Brunauer, S., Emmet, P.H., Teller, E., 1938. Adsorption of gases in mulimolecular layers. J. Am. Chem. Soc. 60, 309-319.

Buurman, P., Jongmans, A.G., 2005. Podzolisation and soil organic matter dynamics. Geoderma 125, 71-83.

Chao, T.T., Sanzolone, R.F., 1992. Decomposition techniques. J. Geochem. Explor. 44, 65-106.

Chenu, C., Plante, A.F., 2006. Clay-sized organo-mineral complexes in a cultivation chronosequence: revisiting the concept of the 'primary organo-mineral complex'. Eur. J. Soil Sci. 57, 596-607.

Cornell, R.M., Schwertmann, U., 1996. The Iron Oxides: Structure, Properties, Reactions, Occurence and Uses. Weinheim, VCH.

Dahlgren, R.A., 1994. Quantification of allophane and imogolite. In: Zelazny, L.W., Amonette, J.E. (Eds.), Quantitative Methods in Soil Mineralogy. Soil Science Society of America, Madison, pp. 430-451.

De Coninck, F., 1980. Major mechanisms in formation of spodic horizons. Geoderma 24, 101-128.

Dungait, J., Hopkins, D., Gregory, A., Whitmore, A., 2012. Soil organic matter turnover is governed by accessibility not recalcitrance. Glob. Chang. Biol. 18, 1781-1796.

Eusterhues, K., Rumpel, C., Kögel-Knabner, I., 2005a. Organo-mineral associations in sandy acid forest soils: importance of specific surface area, iron oxides and micropores. Eur. J. Soil Sci. 56, 753-763.

Eusterhues, K., Rumpel, C., Kögel-Knabner, I., 2005b. Stabilization of soil organic matter isolated via oxidative degradation. Org. Geochem. 36, 1567-1575.

Eusterhues, K., Neidhardt, J., Hädrich, A., Küsel, K., Totsche, K.U., 2014. Biodegradation of ferrihydrite-associated organic matter. Biogeochemistry 119, 45-50.

Farmer, V.C., 1982. Significance of the presence of allophane and imogolite in podzol Bs horizons for podzolization mechanisms: a review. Soil Sci. Plant Nutr. 28 (4), $571-578$.

Farmer, V.C., Russel, J.D., Berrow, M.L., 1980. Imogolite and proto- imogolite allophane in spodic horizons: evidence for a mobile aluminum silicate complex in podzol formation. J. Soil Sci. 31, 673-684.

Gerin, P.A., Genet, M.J., Herbillon, A.J., Delvaux, B., 2003. Surface analysis of soil material by X-ray photoelectron spectroscopy. Eur. J. Soil Sci. 54, 589-604.

Herbauts, J., 1982. Chemical and mineralogical properties of sandy and loamy-sandy ochreous brown earths in relation to incipient podzolization in a brown earth-podzol evolutive sequence. J. Soil Sci. 33, 743-762.

IUSS Working Group WRB, 2015. World Reference Base for Soil Resources 2014, Update 2015. International Soil Classification System for Naming Soils and Creating Legends for Soil Maps. World Soil Resources Reports No. 106. FAO, Rome.

Kaiser, K., Guggenberger, G., 2007. Sorptive stabilization of organic matter by microporous goethite: sorption into small pores vs surface complexation. Eur. J. Soil Sci. 58, 45-59.

Kleber, M., Mikutta, R., Torn, M.S., Jahn, R., 2005. Poorly crystalline mineral phases protect organic matter in acid subsoil horizons. Eur. J. Soil Sci. 56, 717-725.

Kleber, M., Eusterhues, K., Keiluweit, M., Mikutta, C., Mikutta, R., Nico, P.S., 2015. Mineral-organic associations: formation, properties, and relevance in soil environments. Adv. Agron. 130 (chapter one)

Kögel-Knabner, I., Ekschmitt, K., Flessa, H., Guggenberger, G., Matzner, E., Marschner, B., von Lützow, M., 2008. An integrative approach of organic matter stabilization in temperate soils: linking chemistry, physics, and biology. J. Plant Nutr. Soil Sci. 171, $5-13$

Landoulsi, J., Genet, M.J., Yetioman, Y.S., Fleith, S., Liascukiene, I., Mehivier, C., Rouxhet, P.G., 2016. Organic adlayer on inorganic materials: coping with contamination. Appl. Surf. Sci. 383, 71-83.

Lavkulich, L.M., Wiens, J.H., 1970. Comparison of organic matter destruction by hydrogen peroxide and sodium hypochlorite and its effects on selected mineral constituents. Soil Sci. Soc. Am. J. 34, 755-758.

Lehmann, J., Kleber, M., 2015. The contentious nature of soil organic matter. Nature 528, $60-68$

Lundström, U.S., van Breemen, N., Bain, D., 2000. The podzolization process. A review. Geoderma 94, 91-107.

Marín-Spiotta, E., Gruley, K.E., Crawford, J., Atkinson, E.A., Miesel, J.R., Greene, S. Cardona-Correa, C., Spencer, R.G.M., 2014. Paradigm shifts in soil organic matter research affect aquatic carbon turnover interpretations: transcending disciplinary and ecosystem boundaries. Biogeochemistry 117, 279-297.

Marschner, B., Brodowski, S., Dreves, A., et al., 2008. How relevant is recalcitrance for the stabilizatioin of organic matter in soils? J. Plant Nutr. Soil Sci. 171, 91-110.

Masiello, C.A., Chadwick, O.A., Southon, J., Torn, M.S., Harden, J.W., 2004. Weathering controls on mechanisms of carbon storage in grassland soils. Glob. Biogeochem. Cycles 18.

Mayer, L.M., Schick, L.L., Hardy, K., Wagai, R., McCarthy, J., 2004. Organic matte content of small mesopores in sediments and soils. Geochim. Cosmochim. Acta 68, 3863-3872.

Mehra, O.P., Jackson, M.L., 1960. Iron oxides removal from soils and clays by dithionite-citrate system buffered with sodium bicarbonate. In: Clays and Clay Minerals: Proc. 7th. Pergamon Press, London, pp. 317-327.

Mikutta, R., Kleber, M., Torn, M.S., Jahn, R., 2006. Stabilization of soil organic matter: association with minerals or chemical recalcitrance? Biogeochemistry 77, 25-56.

Mikutta, R., Schaumann, G.E., Gildemeister, D., Bonneville, S., Kramer, M.G., Chorover, J., Chadwick, O.A., Guggenberger, G., 2009. Biogeochemistry of mineralorganic associations across a long-term mineralogical soil gradient (0.3-4100 kyr), Hawaiian Islands. Geochim. Cosmochim. Acta 73, 2034-2060.

Mueller, C.W., Kölbl, A., Hoeschen, C., Hillion, F., Heister, K., Herrmann, A.M., Kögel knabner, I., 2012. Submicron scale imaging of soil organic matter dynamics using NanoSIMS - from single particles to intact aggregates. Org. Geochem. 42, 1476-1488.

Munaut, A.-V., 1967. Recherches paleoecologiques en Basse et Moyenne Belgique. Acta Geogr. Lovan. 6, 191.

Ndayiragije, S., Delvaux, B., 2003. Coexistence of allophane, gibbsite, kaolinite and hydroxy interlayered smectite in a perhydrated Andosol. Geoderma 117 (3-4), 203-214.

Oades, J.M., 1988. The retention of organic matter in soils. Biogeochemistry 5, 35-70.

Pamula, E., Rouxhet, P.G., 2003. Bulk and surface chemical functionalities of type III PAN based carbon fibres. Carbon 41, 1905-1915.

Parikh, S.J., Goyne, K.W., Margenot, A.J., Mukome, F.N.D., Calderón, F.J., 2014. Soil chemical insights provided through vibrational spectroscopy. Adv. Agron. 126, $1-148$.

Rouiller, J., Burtin, G., Souchier, B., 1972. La dispersion des sols dans l'analyse granulométrique. Méthode utilisant les résines échangeuses d'ions. ENSAIA Nancy 14 194-205.

Rouxhet, P.G., Brindley, G.W., 1966. Experimental studies of fine-grained micas II. The water content of wet-ground micas. Clay Miner. 6, 219-228.

Rouxhet, P.G., Samudacheata, Ngo, Jacobs, H., Anton, O., 1977. Attribution of the OH stretching bands of kaolinite. Clay Miner. 12, 171-179.

Rouxhet, P.G., Robin, P.L., Nicaise, G., 1980. Characterization of kerogens and study of their evolution by infrared spectroscopy. In: Durand, B. (Ed.), Kerogen. Technip, Paris, pp. 163-190 (Ch. 6). 
Sauer, D., Sponagel, H., Sommer, M., Giani, L., Jahn, R., Stahr, K., 2007. Podzol: soil of the year 2007 - a review on its genesis, occurrence, and functions. J. Plant Nutr. Soil Sci. 170, 581-597.

Schmidt, M.W.I., Torn, M.S., Abiven, S., et al., 2011. Persistence of soil organic matter as an ecosystem property. Nature 478, 49-56.

Shainberg, I., Alperovitch, N.I., Keren, R., 1987. Charge density and Na-K-Ca exchange on smectites. Clay Clay Miner. 35 (1), 68-73.

Siregar, A., Kleber, M., Mikutta, R., Jahn, R., 2005. Effect of sodium hypochlorite oxidation on soils containing poorly crystalline mineral phases. Eur. J. Soil Sci. 56, 481-490.

Six, J., Conant, R.T., Paul, E.A., Paustian, K., 2002. Stabilization mechanisms of soil organic matter: implications for C-saturation of soils. Plant Soil 241, 155-176.

Torn, M.S., Kleber, M., Zavaleta, E.S., Zhu, B., Field, C.B., Trumbore, S.E., 2013. A dual isotope approach to isolate soil carbon pools of different turnover times. Biogeosciences 10, 8067-8081.

Van Breemen, N., Mulder, J., Driscoll, C.T., 1983. Acidification and alkalinization of soils.
Plant Soil 75, 283-308.

Van Ranst, E., Righi, D., De Coninck, F., Robin, A.M., Jamagne, M., 1980. Morphology, composition and genesis of argilans and organans in soils. J. Microsc. 120, 353-361.

Van Ranst, E., Stoops, G., Gallez, A., Vandenberghe, R.E., 1997. Properties, some criteria of classification and genesis of upland forest Podzols in Rwanda. Geoderma 76, 263-283.

Vogel, C., Müller, C.W., Höschen, C., Buegger, F., Heister, K., Schulz, S., Schloter, M., Kögel-Knabner, I., 2014. Submicron structures provide preferential spots for carbon and nitrogen sequestration in soils. Nat. Commun. 5.

von Lutzöw, M., Kögel-Knabner, I., Ludwig, B., Matzner, E., Flessa, H., Ekschmitt, K., Guggenberger, G., Marschner, B., Kalbitz, K., 2008. Stabilization mechanisms of organic matter in four temperate soils: development and application of a conceptual model. J. Plant Nutr. Soil Sci. 171, 111-124.

Wada, K., 1989. Allophane and imogolite. In: Dixon, J.B., Weed, S.B. (Eds.), Minerals In Soil Environments, 2nd Edition. SSSA Book Series $N^{\circ} 1$, Madison, Wisconsin, pp. 1051-1087. 